\title{
Role and Influence of Innovative Education in Sports Colleges Football Teaching
}

\author{
Tobo Xinbayaer \\ Jining Normal University, Wulanchabu, Inner Mongolia, 012000, China
}

Keywords: Innovative education, Sports colleges, Football teaching, Aapplication, Role.

\begin{abstract}
In this stage, in the training of highly qualified sports professionals, physical education (PE) plays an active role. In order to better adapt to the trend of the times, education reform improves the requirements for personnel. However, education reform usually takes the traditional concept as the core, so that it is rare to cultivate students' humanity and develop their humanistic quality, especially $\mathrm{PE}$ reform training students' innovative and practical ability. Therefore, in order to fully develop innovative and high-quality sports professionals, we must carry out innovative education with characteristics.
\end{abstract}

\section{Introduction}

In the process of the development of physical education in China, students in sports colleges are the important reserve force. However, under the influence and role of traditional sports teaching philosophy, fostering sports talents receives a negative impact, seriously neglecting the comprehensive training of students' creative ability, and ultimately making most of sports students hard to gain a foothold in society. So, in the current PE teaching reform, we must develop innovative education, which is an important way of scientific development of college sports teaching. Developing innovative education can not only actively change the traditional concept of PE, but also enhance the quality and efficiency of sports teaching, and comprehensively train sports professionals.

\section{Brief introduction of innovative education}

\section{Connotation of innovative education}

The so-called innovative education specifically refers to the targeted and planned education for students' innovation and spirit carried out during the process of teaching activities. And innovative education needs to constantly update educational and teaching related philosophies, emphasize on students' ability to master the technical knowledge and skills, and fully develop students' creative thinking while exploring deeply students' potential [1].

Application of innovative education is mainly aimed to achieve the comprehensive development of students. To continue to adapt to the needs of social development, innovative education needs care and attention for students' learning, and teaches students about survival and creativity skills. However, to be noted that, it's not allowed ignoring the importance of the exam because of this. Because the exam is also an important part of innovative education, able to truly reflect the education information and students' learning conditions.

\section{Innovative education in sports teaching}

Currently, in the teaching process of sports colleges, innovative education is widely used, particularly in many traditional sports including basketball, volleyball and soccer. This can not only stimulate students' interest, but also activate the classroom atmosphere, so that students' initiative to participate in will be enhanced; they are more motivated to acquire the relevant skills in self-directed learning, their physical ability will be enhanced and they will continue to cultivate personal sentiment, to better adapt to social development. However, in the process of innovative education applications, there exists certain blindness, and teachers do not really feel the true meaning of innovative education, so 
its application in the classroom is relatively stiff, and difficult to achieve the effect of innovative education.

\section{Problems of traditional football teaching in sports colleges}

\section{Ignore the principal role of students in classroom}

At present, in the education of sports colleges, “more on teaching and less on learning” is a very common situation. While in the process of football education, teachers blindly pursue the completion of teaching tasks, therefore, they attach great importance to knowledge teaching, but seriously neglect cultivating students' independent learning ability. Influenced and constrained by traditional teaching philosophy, teachers' education awareness always remains on the surface, seriously derailing with the nature. Physical education needs to train students' initiative and activity, and encourage their independent study [2]. In addition, teachers should enhance their cultural quality, properly guide students to actively think and imitate in the classroom, make learning and exercises interacting, take students as the main teaching subjects, and then give full play to the leading role of teachers, so that students can better participate in the learning, and master appropriate skilled movements.

\section{Ignore sports items education}

In sports colleges, students from competitive sports schools occupy a large proportion, but their knowledge level and humanistic quality are not high, so in order to change the current status of teaching, the most important thing is to pay more attention to education work. Transform teaching into education, improve students' scientific and cultural quality, and actively teach students about appropriate learning methods and behaviors, and so on. Additionally, within sports teaching rules, normalize students' ethical behaviors, make them respect others and themselves, and enable them to ultimately establish the correct moral values.

\section{Ignore the importance of theoretical knowledge}

At this stage, when carrying out football teaching, most of sports colleges always pay attention to training students' skills and tactical levels, and pursuing the technical examination results [3]. Therefore, they seriously neglect quality education, especially the training of creativity ability, and combination ability of theory and practice. And in the football teaching, teachers just impart representation of football skills, so that students' cognitive process of football is seriously neglected, difficult to achieve the ultimate goal of PE professionals training, or even seriously affecting students' mastery of professional theoretical knowledge of football.

\section{Single teaching method}

Football teaching in sports colleges always takes materials and textbooks as the core, which makes teaching content very boring. At the same time, teaching methods are also very single and rigid, while in terms of teaching organization, order is overemphasized, and football skills normalization and football practice density are focused. Therefore, football classroom teaching atmosphere is seriously neglected, and then it is difficult to stimulate students' interest in learning. In addition, the interaction between learning and training cannot be effectively achieved, so it is difficult to train students to form exercise habits, seriously impacting the achievement of teaching objectives, combat students' initiative to learn football, and having a negative impact on sports teaching effect.

\section{Application of innovative education in football teaching of sports colleges}

\section{Actively change traditional PE philosophy}

First, the teaching concept taking students as the subject. Compared with traditional education, the biggest difference is innovative education takes students as the subjects in football teaching activities. 
All teaching activities include teaching and learning. While in the traditional football teaching, teachers will complete teaching activities alone, relatively simply impart football knowledge, and neglect the initiative of students to certain degree, therefore, it is difficult to highlight students' dominant position. This teaching method allows students to pay more attention to learning outcomes, but have no enthusiasm in the exploration of new knowledge, eventually leading to students' football technical skills and innovative spirit and ability are hard to be improved. Thus, in innovative education of football teaching, we must change the original PE concept, and truly implement the subjectivity of students [4].

Second, practice "teaching for learning" concept. Football innovative education should not only reflect the dominant position of students, but also not to ignore the leading role of teachers. In innovative education, teachers take preaching and imparting as the means of teaching, but cannot regard then as the purpose of education. In this way, we can provide more targeted guidance to students and enable them to better learn football through active learning, and positively enhance their innovation and practical ability.

\section{Innovate football teaching modes}

First, the teaching situation analysis teaching. What has the direct impact on football classroom teaching is football class preview, which enables students to correctly understand and grasp football skills. In football teaching, teachers need to arrange students to preview before class, to ensure that students have a certain understanding and knowledge about football skills they are going to learn. But before the demonstration, the teacher should ask students questions related to football skills. In practical demonstration, require students to carefully observe. Among which, when the teacher demonstrates the front arch pass action, he should in advance requires students to observe the ready position before passing the ball, the force order, the hitting point, the direction of the ball and the foot position for passing the ball, etc. And after completion of the demonstration, students need to answer questions raised before. As a result, the pass action will be impressed in their minds. And according to students' answers, the teacher needs to explain the action which is prone be easily mistaken, thereby strengthening the students' awareness of the action, to achieve the process from emotional to rational understanding.

Second, teaching emotional innovative teaching. In football classroom teaching, teachers must pay attention to cultivating students' ability to design and organize the classroom, reserving the room for students to freely choose, actively encouraging students to explore, bravely practice, and resolve problems of real football through the use of football knowledge and experience they already have. Students' own knowledge and skills as well as their own quality are accumulated and enhanced continuously, and their ability to identify, analyze and resolve problems is increased at the same time. Therefore, in this mode of football teaching, students will be able to actively take their initiative, follow the textbook or teachers' suggestions to design practice forms and methods. As a result, it is able to actively induce and inspire students to better participate in the football teaching activities, highlight their dominant position, exhibit the guiding role of teachers, continue to meet the needs of students' desire to learn, and give full play to students' imagination and creativity.

\section{Diversified teaching}

First, the scene teaching. In football teaching, teachers should use a variety of conditions to ensure that students can take the initiative to enter the teaching scenes, make them put forward doubts, problems and divergent thinking, and guide their thoughts to explore and experience. For example, in the double-pass technical teaching, teachers can design problem scenes. For example, in class football match, if the defense is very tight, so what methods should be used to break the defense? In addition, teachers can also arrange two students to practice double-pass, in which one is the defender. Throughout the process, some students use wall-pass method, and some use diagonal-pass method-to break the tight defense. Based on this, the teacher should also arrange students who are qualified to 
demonstrate and guide by the side, so that students are more proficient with football skills, and classroom atmosphere becomes more active.

Second, the exploring teaching. In football classroom innovative education, the exploring teaching method plays an important role. After the correct guidance of teachers, students can take advantage of their experience, and adopt divergent thinking, to innovate football skills [5]. Among which, based on students' existing experience and knowledge about football, conduct football skills and movement exercises, use individual body parts to hit the ball, such as kicking by feet or head and so on. In addition, teachers can guide students to explore in the process, and students feel a sense of accomplishment of exploration through their own experience, and then get the appropriate knowledge, improve their interest in learning football, and increase their confidence in learning football knowledge.

Third, the interactive teaching. In football teaching, the teacher is the organizer, and also a guide. Therefore, teachers should give full play to the initiative of students, and thus reflect the dominant position of students. And in a relaxed and democratized learning atmosphere, through discussion with each other, and developing thinking, students specify football teaching and practice methods during their discussion, which is teaching re-creation beyond football teaching materials. Wherein, in the course of conducting offensive tactics teaching, students are able to consider their individual strengths to organize appropriate attack methods. In terms of defense, should take the "man to man" approach, in which the attacker needs to use a variety of attack methods, such as overlapping cover, to break the defense. In this discussion, practice and application, repeated learning allows students to efficient improve their football skills and tactical ability. In the teaching process, reasonable cooperation and discussion and democratically planned teaching methods can not only allow students play their individual capacities among the group, also master football knowledge and practical applications, to better develop and train students' creative ability.

\section{Conclusive analysis}

Traditional sports teaching concepts have a negative impact on football teaching in sports colleges, seriously neglecting cultivating students' innovative ability and practice ability. At this stage, the football teaching in sports colleges does not truly reflect the dominant position of students, but just focuses on the knowledge imparting, and neglects the importance of students' independent study. In this background, football teaching atmosphere is relatively tense, and interaction between teachers and students is seriously lacking, which will eventually affects students' active learning ability.

While the innovative education of football teaching stands from a new perspective, and innovates teaching and talents training concepts. There are fundamental differences compared with traditional sports teaching concepts. Football teaching innovative education emphasizes personal equality, particularly to create a better atmosphere for students. Innovative football education can dig and cultivate students' creative ability and practical ability.

\section{Conclusion}

In summary, in football teaching of sports colleges, innovative education can improve the overall quality of students, which can not only positively drive the development of football education in sports colleges, but also promote the deep teaching reform in sports colleges. This paper in detail analyzes innovative education, proposes the existing problems of football teaching in sports colleges, and ultimately puts forward effective solutions. Application of innovative education in football teaching in sports colleges has an important role in the further development of football education.

\section{References}

[1] Fu Qiang. Application of Innovative Education in Football Teaching of Sports Colleges, Fighting, 2013,5 (7): 72-74. 
[2] Pan Dali. On Innovative Education in Football Teaching of Sports Colleges, Success (Education Edition), 2010 (8): 95-96.

[3] Li Yalin. How to Conduct Innovative Education in Football Teaching of Sports Colleges, Physical Space-Time, 2015 (20): 176.

[4] li Jibiao. On Innovative Education of Football Teaching Methods in High School, Science Times, 2012 (3): 310-311.

[5] Zhang Dapeng. On Application of Innovative Education in Football Teaching of Technical Colleges, Research on Course Education (new teachers' teaching), 2013 (1): 295. 